\title{
Atypical Early Recurrence after Robot-Assisted Radical Cystectomy: Port-Site Metastasis
}

\author{
Hakan Anil Ekrem İslamoğlu Çağatay Özsoy Mutlu Ateş \\ University of Health Sciences, Urology, Antalya Training and Research Hospital, Antalya, Turkey
}

Murat Savaş

\section{Key Words}

Metastasis • Invasive bladder cancer • Adjuvant therapy •

Metastasectomy

\section{Abstract}

Port-site metastasis (PSM) have gained importance due to increasing number of robot-assisted radical cystectomy (RARC). To the best of our knowledge, there are 13 cases in the literature, with only one reporting, treatment modality and oncological outcome. There is no consensus about the treatment for PSM developing after RARC. Here, we report a PSM occurring in the early period after RARCand recommend a treatment modality.

(c) 2020 The Author(s) Published by S. Karger AG, Basel

\section{Introduction}

Radical cystectomy with extended pelvic lymph node dissection is considered as the standard treatment for localized muscle invasive bladder cancer and recurrent high-grade noninvasive disease [1]. The number of robot-assisted radical cystectomy (RARC) has increased in the last decade [2]. In spite of this popularity, there is no consensus about the superiority of open radical cystectomy.

\section{KARGER}

Fax +4161306 1234

E-Mail karger@karger.com

www.karger.com
(C) 2020 The Author(s)

Published by S. Karger AG, Basel Upen access

This article is licensed under the Creative Commons AttributionNonCommercial-NoDerivatives 4.0 International License (CC BYNC-ND) (http://www.karger.com/Services/OpenAccessLicense) $\mathrm{NC}-\mathrm{ND}$ ) (http://www.karger.com/Services/OpenAccess License).
Usage and distribution for commercial purposes as well as any distribution of modified material requires written permission.
Port-site metastasis (PSM) are an uncommon complication of minimal invasive surgery. The incidence of PSM in urological laparoscopy is reported as $0.9 \%$ for genitourinary malignant disease [3]. Only 13 cases with PSM after RARC have been reported in the literature. In this study we report a male patient with PSM which occurred in the postoperative 8th week after RARC.

\section{Case Presentation}

A 68-year-old male patient was referred to our clinic because of muscle invasive transitional cell carcinoma (TCC) of the bladder. His physical examination was unremarkable and routine laboratory studies did not document any abnormalities. Abdomino-pelvic and chest computer tomography were performed for clinical staging, which was T2NOM0. There was no local invasion or distant metastasis identified in any visceral organ or lymph node. So we decided to perform RARC. Five ports were used; the 8 - $\mathrm{mm}$ camera port was placed $5 \mathrm{~cm}$ above the umbilicus, two 8 $\mathrm{mm}$ robotic arm ports were placed on each side of the midclavicular line, one $8 \mathrm{~mm}$ robotic arm port was placed at the right anterior axillary line, and one $12 \mathrm{~mm}$ assisting port was placed $6 \mathrm{~cm}$ above the umbilicus between the camera port and left robotic arm port. Radical cystectomy with extended pelvic node dissection and intracorporeal orthotopic neobladder procedure was performed with the da Vinci ${ }^{\circledast}$ surgical system lasting 5 hours and 30 minutes. Radical cystectomy and lymph nodes material was placed in a Laparoscopic Retrieval Bag ${ }^{\mathrm{TM}}$ (Richard Wolf, USA). The camera port incision was enlarged and the surgical specimen was

Hakan Anil

University of Health Sciences, Urology Antalya Training and Research Hospital

Varlik Mahallesi

TR-07100 Antalya (Turkey)

E-Maildr.hakananil@gmail.com 

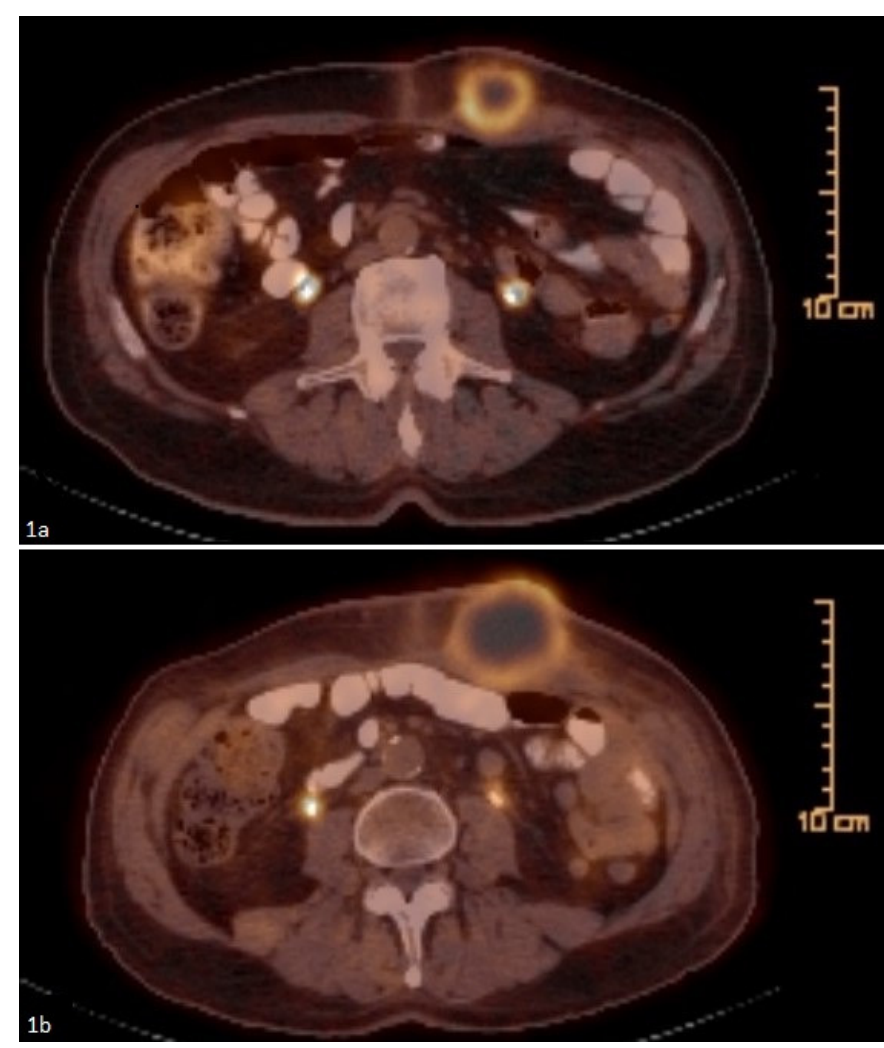

Fig. 1. a 18-FDG PET/CT scan of an axial image of showed that $18 \times 15 \mathrm{~mm}$ a hypermetabolic lesion invaded left rectus abdominis muscle. b Partial response after combination therapy.

removed. Postoperative recovery was uneventful, and the patient was discharged on the 10th day following surgery. Histopathological investigation of radical cystectomy material indicated highgrade, deep muscle invasive TCC. The 25 lymph nodes were all reactive, surgical margins were negative and pathological stage was T2bN0.

Eight weeks after surgery, the patient had admitted to our clinic with a small, tender, well-circumscribed $3 \times 2 \mathrm{~cm}$ mass at the assistant port site. $18 \mathrm{~F}$-flurodeoxyglucose positron-emission computed tomography (FDG-PET/CT) imaging observed a hypermetabolic lesion with $18 \times 15 \mathrm{~mm}$ dimensions invading the rectus muscle of the abdominal anterior wall (fig. 1a). A core needle biopsy was performed, and pathological examination reported high-grade TCC metastasis. Following consulting with medical oncology and radiation oncology departments, we decided to administer chemotherapy. After administration of 3 cycles of cisplatin and gemcitabine protocol, there was no decrease in the dimension of metastatic bulk. An external-beam radiotherapy (in total 40 Gy in 16 fractions) combined with cisplatin and paclitaxel was planned due to the lack of response to initial therapy. After the second stage treatment modality, partial response was observed on PET/CT imaging (fig. 1b). So we decided to perform a wide surgical excision, after 7 weeks of combination therapy. During the operation, the tumor had invaded the left rectus abdominis mus-
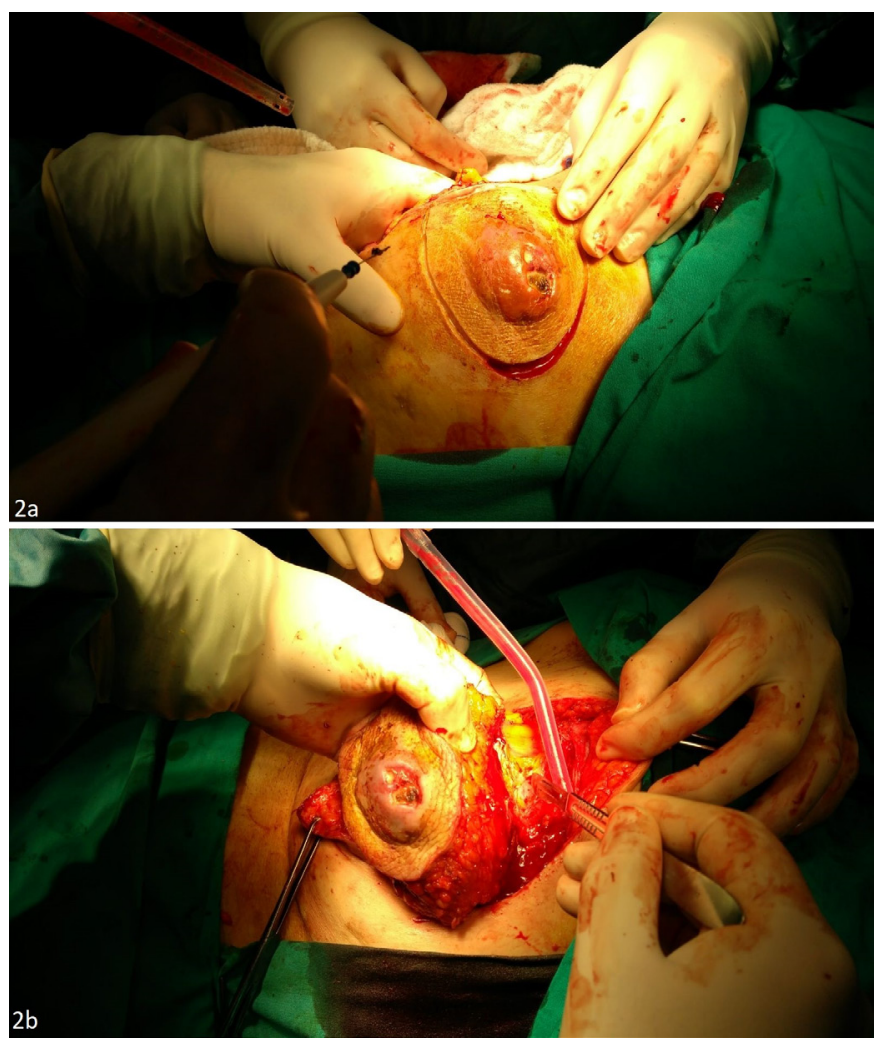

Fig. 2. a Macroscopic appearance of PSM. b Intraoperative view of the wide surgical excision.

cle but there was no peritoneal involvement (fig. 2). The removed specimen was $5 \times 4 \mathrm{~cm}$ tumor in diameter and fascial defect was closed with dual mesh. After histopathologic examination, the tumor was reported as a TCC metastasis. The follow-up was 12 months and there was no local recurrence or distant metastasis.

\section{Discussion}

The incidence of PSM after RARC is less than $0.5 \%$, with higher rates in RARC when compared with other genitourinary cancers [4]. Though there are 13 cases reported in the literature till now, it is thought that, this number involves bias [5]. In a 31-case RARC series from our clinic, 1 patient had PSM.

There are different theories relating to the formation mechanism of PSM. These include intrinsic theories such as tumor aggressiveness, local processes in the wound and hot immune response. Extrinsic factors include inhibition of the peritoneal immune response by $\mathrm{CO}_{2}$ used in pneumoperitoneum, seeding of tumor cells in the perito- 
neal cavity by repeated gas insufflation and desufflation, and repeated entry and exit of laparoscopic instruments [6]. Additionally, a study by Hussein et al. [7] reported that PSM occurring in the early period after RARC is related to tumor aggressiveness instead of type of surgery. In our case, the metastasis occurred at the assistant port. This port was used for insufflation and desufflation during the surgery. Also aspiration catheter and laparoscopic instruments were used through this port. The occurrence at this port with highest entry of insufflation and laparoscopic instruments supports the available theories.

PSM is an atypical recurrence after radical cystectomy, with no consensus on treatment. Of the 13 cases in the literature, only one reported their treatment modality and shared follow-up duration. Khetrapal et al. [4] administered 3 cycles of chemotherapy, containing cisplatin and gemcitabine, and partial response obtained. After the chemotherapy, surgical excision with radiother- apy were applied for their patients. They emphasized that treatment must be patient-based, and reported the patient was recurrence-free during 2 years of follow-up. We did not achieve a response after 3 cycles of chemotherapy, so we combined radiotherapy with another chemotherapy protocol and partial response was received. Finally, we performed a wide surgical resection and patient was recurrence-free after 12 months.

In conclusion, PSM after RARC is very rarely reported. Aggressiveness of the tumor and factors related to laparoscopy trigger seeding of tumor to the port site. We believe that it is necessary to perform insufflation through a port with fewer entries and exits of instruments, where it must use appropriate technique to retrieve surgical specimen. There is a need for case series and meta-analysis for treatment protocols and recurrence-free survival rates for PSM.

\section{References}

1 Alfred Witjes J, Lebret T, Compérat EM, Cowan NC, De Santis M, Bruins HM, Hernández V, Espinós EL, Dunn J, Rouanne M, Neuzillet Y, Veskimäe E, van der Heijden AG, Gakis G, Ribal MJ: Updated 2016 EAU guidelines on muscle-invasive and metastatic bladder cancer. Eur Urol 2017;71:462-475.

-2 Ahmed YE, Hussein AA, Kozlowski J, Guru KA: Robot-assisted radical cystectomy in men: technique of spaces. J Endourol 2018; 32(S1):S44-48.

3 Micali S, Celia A, Bove P, De Stefani S, Sighinolfi MC, Kavoussi LR, Bianchi G: Tumor seeding in urological laparoscopy: an international survey. J Urol 2004;171:2151-2154.
4 Khetrapal P, Tan WS, Lamb B, Nathan S, Briggs T, Shankar A, Ramachandran N, Freeman A, Mitra A, Kelly JD: Port-site metastasis after robotic radical cystectomy: a systematic review and management options. Clin Genitourin Cancer 2017;15:440-444.

$\checkmark 5$ Jancke G, Aljabery F, Gudjonsson S, Hosseini A, Sörenby A, Wiklund P, Liedberg F: Port-site metastasis after robot-assisted radical cystectomy: is there a publication bias? Eur Urol 2018;73:641-642.
6 Collins JW, Hosseini A, Adding C, Nyberg T, Koupparis A, Rowe E, Perry M, Issa R, Schumacher MC, Wijburg C, Canda AE, Balbay M, Decaestecker K, Schwentner C, Stenzl A, Edeling S, Pokupi S, D'Hondt F, Mottrie A, Wiklund PN: Early recurrence patterns following totally intracorporeal robot-assisted radical cystectomy: results from the EAU Robotic Urology Section (ERUS) Scientific Working Group. Eur Urol 2017;71:723-726.

7 Hussein AA, Saar M, May PR, Wijburg CJ, Richstone L, Wagner A, Wilson T, Yuh B, Redorta JP, Dasgupta P, Khan MS, Menon M, Peabody JO, Hosseini A, Gaboardi F, Mottrie A, Rha KH, Hemal A, Stockle M, Kelly J, Maatman TJ, Canda AE, Wiklund P, Guru KA: Early oncologic failure after robot-assisted radical cystectomy: results from the International Robotic Cystectomy Consortium. J Urol 2017;197:1427-1436. 